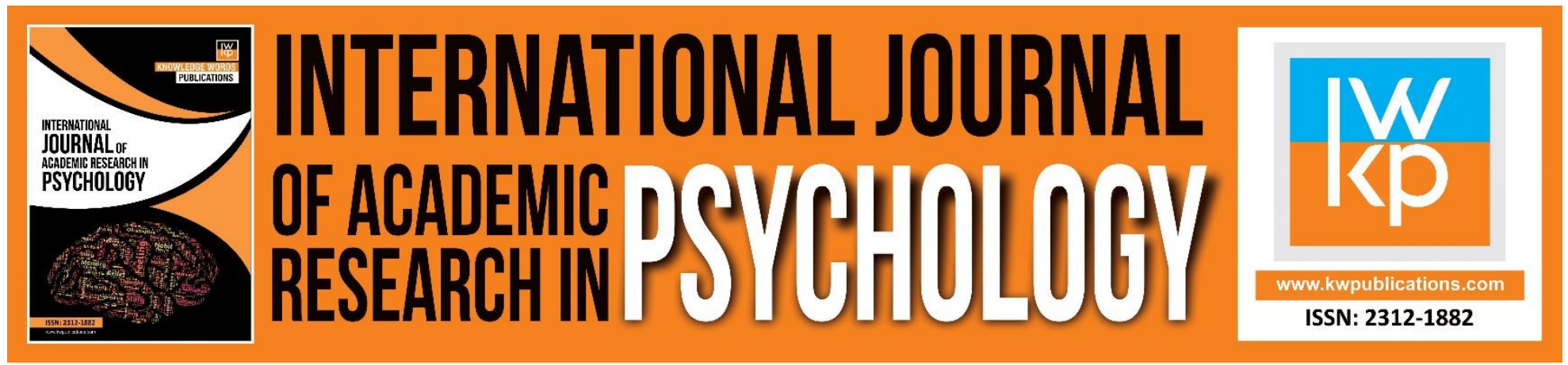

\title{
Self Construal and Mental Health of Women in India
}

\section{Ruchika Varma \& Megha Gupta}

To Link this Article: http://dx.doi.org/10.46886/IJARP/v7-i1/7206 DOI:10.46886/IJARP/v7-i1/7206

Received: 09 January 2020, Revised: 13 February 2020, Accepted: 14 March 2020

Published Online: 27 March 2020

In-Text Citation: (Varma \& Gupta, 2020)

To Cite this Article: Varma, R., \& Gupta, M. (2020). Self Construal and Mental Health of Women in India. International Journal of Academic Research in Psychology, 7(1), 17-28.

\section{Copyright: (c) 2020 The Author(s)}

Published by Knowledge Words Publications (www.kwpublications.com)

This article is published under the Creative Commons Attribution (CC BY 4.0) license. Anyone may reproduce, distribute, translate and create derivative works of this article (for both commercial and non-commercial purposes), subject to full attribution to the original publication and authors. The full terms of this license may be seen

at: http://creativecommons.org/licences/by/4.0/legalcode

\section{Vol. 7, No. 1, 2020, Pg. 17 - 28}

Full Terms \& Conditions of access and use can be found at https://kwpublications.com/pages/detail/publication-ethics 


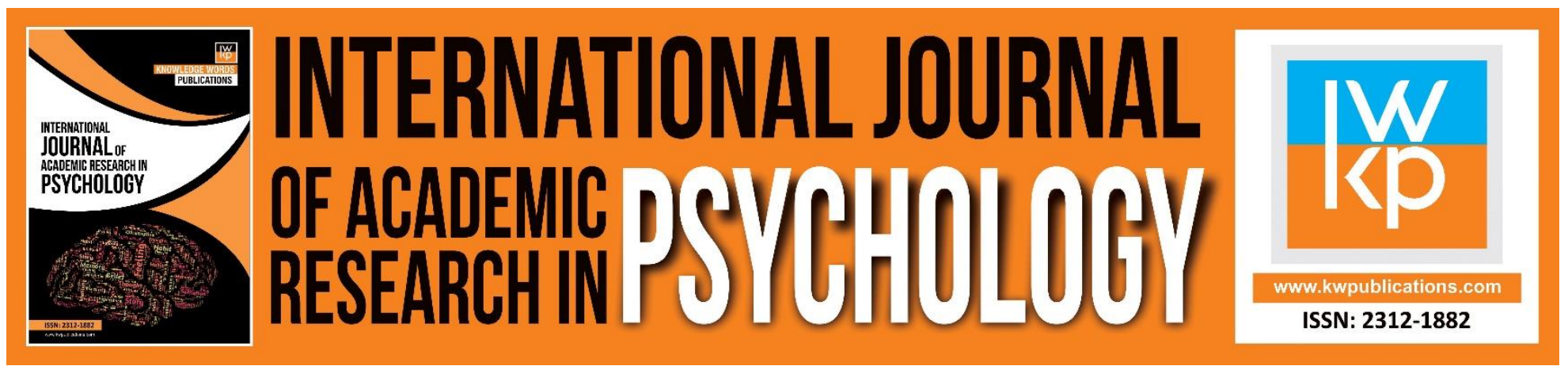

\title{
Self Construal and Mental Health of Women in India
}

\author{
Ruchika Varma* \& Megha Gupta** \\ * Asstt. Professor, Deptt. of Psychology, CMP PG College, University of Allahabad 211002. \\ ** Research Scholar, National Institute of Mental Health and Neuroscience, Bangalore 560029. \\ Email: ruchikapsy@yahoo.co.in,meghagupta3003@gmail.com
}

\begin{abstract}
The present paper discusses the nature of self and its relationship with the mental health problems in women. Data were collected through in-depth interviews. Twenty women in the age range of 30 to 45 years were interviewed using an open ended interview schedule. The nature of self was assessed using Singeli's Self Construal Scale (1994). The women in the sample reported that mental health problems in women originate from the psychosocial causes such as role conflicts, role expectations and role burden. Sixty-seven per cent women showed an inclination towards independent self whereas thirty-seven per cent reflected an interdependent self. The results on in depth interviews however, showed that they felt pressurized to adhere to the traditional social roles and norms. Women despite willing to adapt individual selves could not do so because of the guilt induced by the family and society for not following a traditional image thereby reflecting interrelation self of women in Indian society. This state of confusion was a major cause of mental health problems in women. The implications of the study were discussed in the light of past researches.
\end{abstract}

Keywords: Self Concept, Independent Self, Interdependent Self, Mental Health.

\section{Introduction}

Mental health is defined as equilibrium between the individual and the environment, constituting an integral part of overall health (World Health Organization, 2001). It is "a state of well being in which the individual realizes his or her own abilities, can cope with the normal stresses of life, can work productively and fruitfully, and is able to make a contribution to his or her community. "With the National Mental Health Program in place since August 1982, subsequent research has yielded that a gender neutral policy is inadequate to address the needs of those experiencing poor mental health. A number of researchers have proposed that women's mental health cannot be taken care of in isolation with the psychosocial factors that, by and large, contribute to it. Psychosocial factors, as defined in the Encyclopedia of Behavioural Medicine, are "influences that affect a person psychologically or socially. These are multidimensional constructs encompassing several domains such as mood status (anxiety, depression, distress, and positive affect), cognitive behavioral responses (satisfaction, self-efficacy, self-esteem, and locus of control), and social factors (socioeconomic status, education, employment, religion, ethnicity, family, physical attributes, locality, relationships with others, changes in personal roles, and status)," (Suzuki \& Takei, 2013). 
INTERNATIONAL JOURNAL OF ACADEMIC RESEARCH IN PSYCHOLOGY

Vol. 7, No. 1, 2020, E-ISSN: 2312-1882 @ 2020 KWP

World Health Organization (1981) has also positioned the definition of mental health in its report on the Social Dimensions of mental health which states that "Mental Health is the capacity of the individual, the group and the environment to interact with one another in ways that promote subjective well being, the optimal development and use of mental abilities (cognitive, affective and relational), the achievement of individual and collective goals consistent with justice and the attainment and preservation of conditions of fundamental equality".

This definition has special relevance for in relation to women's mental health because it stresses the complex web of interrelationships that determine mental health and goes beyond the biomedical model. It also acknowledges the crucial role of social context and emphasize on the role of justice and equality in determining mental well being.

Globally research has indicated that mental health problems are precipitated and maintained in women due to psychosocial factors. Research analysis by Vindhya (2007) on the two decades of research on gender in psychology was done and the major psychosocial variables were classified into 8 categories which were work family interface, mental health of women, violence against women, reproductive health, gender linked attributions, sexuality, aging and widowhood and marriage and motherhood. It has been reported in the researches that there is a greater prevalence of depression, somatoform and dissociative disorders in women (Vindhya et al., 2001).

With the globalization and consequent social change, the women started stepping out of their homes for financial reasons, for gaining a status in the society and for developing their hidden potentials. But this change placed her in more conflicting situations. The role of a working woman on one hand gives her a sense of economic security and independence but on the other hand, somewhere she is not comfortable in these conflicting roles demanding situations. The National Crime Record Bureau Reports (NCRB, 2018) has indicated a tremendous increase in the nature of crime against women during this period, a special category being added is the Crime by Husband and his Family. This evidently proves that changes in women are educational and employment status was directly affecting the family scenario. These changes in the social scenario have in many ways increased the general vulnerability to mental health disturbances. It has been reported in the researches that physical abuse of women, especially by husband is prevalent even in the $21^{\text {st }}$ century in India (Dutt \& Noble, 1982: Kumar, Gupta \& Abraham, 2002; Rao, 1997). This led to disintegration of already fragile self esteem of women and creating conditions of psychological distress (Basu, 2012).

Education and employment are two important variables in maintaining the self esteem of women. Mental health consequences of employment on women have been investigated in several studies by comparing groups of women who are gainfully employed and those who are mainly engaged in domestic activities (Aminabhavi \& Kulkarni, 2000; Kumari \& Singh, 2000; Mathur \& Bharti, 2001; Aujla, 2002). Moreover, the experiences of self-worth, autonomy and competence, financial security, physical and sexual safety, all essential for mental wellbeing, are denied to a large number of Indian women in rural and even urban setting. Violation of women's rights, specifically their reproductive rights, has a cumulative effect on the disability caused by poor mental health. A woman's poor mental health not only causes damage to her but has far-fetched implications primarily roots from the role of a mother or caregiver (Afifi, 2007). Studies from different cities of India indicates the role of conflict with mother-in-law and husband, verbal and physical abuse, poverty, alcoholic or abusive partner, raising a child with special needs, intimate partner violence, and inadequate support for child care, were most vulnerable to mental health disorders (Kermode et al., 2007). There is comparatively paucity of research indicating the changes in the roles of other family 
INTERNATIONAL JOURNAL OF ACADEMIC RESEARCH IN PSYCHOLOGY

Vol. 7, No. 1, 2020, E-ISSN: 2312-1882 @ 2020 KWP

members as a result of women's employment. Thus, there is a need to look at mental health through a gender-sensitive lens as this will be in interest of the society at large.

\section{Nature of Self and Mental Health of Women}

For years, Western researchers have assumed a single model of the self what has been termed the independent self-construal (Markus \& Kitayama, 1991). The underlying principle that shapes the independent self-construal is the premise that the person is essentially separate from others. The primary components of the independent self-construal are one's unique traits, abilities, preferences, interests, goals, and experiences, and these are differentiated from social contexts, interpersonal relationships, and group memberships. To maintain and enhance this independent view of the self one must maintain a sense of autonomy from others and "be true to one's own internal structures of preferences, rights, convictions, and goals" (Markus \& Kitayama, 1994, p. 459).

In contrast, the notion of the interdependent self-construal holds that the person is connected to others, so that the self is defined, at least in part, by important roles, group memberships, or relationships. For individuals with this self-construal, representations of important relationships and roles share the self-space with abstract traits, abilities, and preferences. To maintain and enhance this interdependent view of the self, individuals will tend to think and behave in ways that emphasize their connectedness to others and that strengthen existing relationships. According to Cross (2016) Self-construal refers to the grounds of self-definition, and the extent to which the self is defined independently of others or interdependently with others. Initially, the term derived from perceived cultural differences in the self. Westerners were thought to have an independent self-construal, which is characterized by separateness from others, by attention to one's abilities, traits, preferences, and wishes, and by the primacy of one's individual goals over those of in-groups. East Asians were thought to have an interdependent self-construal, which is characterized by a sense of fundamental connectedness with others, by attention to one's role in in-groups, and by the primacy of group goals over one's individual goals. Later, a third characterization, the relational self-construal, was proposed; it represents the ways that people may define themselves in terms of close, dyadic relationships. Social and cultural psychologists now view these as three dimensions of the self, which virtually all people construct to some degree. Cultural differences in self-definition arise through differences in the relative strength or elaboration of this self-construal. Consequently, the literature on self-construal can seem somewhat confusing: self- construal is described at times in terms of very different understandings of the self in different cultures, and at other times in terms of universal dimensions (independent, relational, or interdependent) that vary in strength in different cultures. The self construal of Indian women has undergone transitional changes in the recent past. Traditionally Indian self in general and Indian women's self in particular were highly interdependent or relational. But due to social changes and changes in the roles executed by women in her psychosocial environment, the women's self concepts are also changing and moving towards individualist. The impact of broader socio cultural changes can be seen in the women self also. Nature of self is an important indicator of a person's way of doing in the society. The female self in patriarchal societies are defined by the societal norms, values and culture. Traditionally, even when women tries to redefine their selves and identity they always try to fit in the already existing moulds and remains satisfied in their "being in relation." Wills and Petrakis (2019) did a systematic review of research on mother's mental health, well being and motherhood. Findings indicated that the self is an important construct in transition to motherhood. It was found that women are more likely to have a relational 
self-construal than men. Although relational self- construal is not associated with life satisfaction yet is often a moderating variable for wellbeing.

Maas et al. (2019) studied the relationship between self construal, acculturation and autonomyconnectedness and the relationship between autonomy- connectedness and psychopathological symptoms. It was found that on Dutch sample, independent self construal was positively associated with self awareness and capacity for managing new situations and was negatively associated with sensitivity to others. Moreover an interdependent self construal was negatively associated with self awareness and capacity for managing new situations.

Women's dependency has been a widely debated topic around the world. Back in the 60s-80s, women were limited to their household chores, child rearing practices and were financially dependent on men, and the concept of women dependency on men was phenomenological and acceptable. But when 90s arrived with the drive of women empowerment; women education flourished, they became financially independent and balanced work and personal lives. The concept of women dependency then started confusion and displease among the "new independent women". Cinderella Complex is a psychological syndrome that states women are unconsciously driven to be dependent on a dominant figure (preferably male). Relational Theory in relation to Cinderella complex marks distinction in emotional development of men and women. It states that women are primarily driven to connect with others (Saha \& Safri, 2016).

With the above research background and understanding the relationship between self construal and mental health of a person, the present study has been designed on the following objectives:

- To understand qualitatively the concept and causation of mental health problems in women.

- To assess the nature of self construal of women.

- To outline the relationship between nature of self and causes of mental health problems in women.

\section{Method}

Sample: The in depth qualitative interviews of 20 women in the age range of 30 to 45 years with at least one child. The sampling was purposive and 8 women were working as a professional at work place for about 6 hours and 12 women were homemakers. These women were residents of Allahabad City in North India and belong to upper middle socioeconomic class of the society. The mean-age of the respondents was 38.8 years. The minimum educational status of the sample was undergraduate and maximum post graduate level.

Measures

An in-depth interview schedule was prepared to assess the meaning and causes of mental health problems in women. In order to understand the women's notions on causes of mental health problems, probing was done and the respondents were asked to elaborate on the role of various psychosocial correlates on the mental health of women. Singelis (1994) self construal scale was also administered to see the nature of self of Indian women. However, in many instances during the interview the reflection of self was also observed and is therefore reported in the results wherever required.

\section{Procedure}

Twenty women in the sample were individually approached. A prior appointment was fixed and a time slot of around 90 minutes was fixed for the interview session. Rapport was established with the respondents and the purpose of the research was explained to them. Consent was also taken from 
INTERNATIONAL JOURNAL OF ACADEMIC RESEARCH IN PSYCHOLOGY

Vol. 7, No. 1, 2020, E-ISSN: 2312-1882 @ 2020 KWP

the respondents. When it was found that the respondents were comfortable with the setting, the interview schedule was started and then they were first asked to give their responses on Self Construal Scale. Little probing was done wherever required. The responses were recorded for the further use. The responses were later on transcribed and used for interpretation of results. The thematic analysis was done to delineate major findings from the data.

\section{Results}

The data obtained from the respondents were both quantitative and qualitative in nature. The responses obtained on Self Construal Scale were quantitative and were

interpreted accordingly. The responses on self construal scale indicates that the $33 \%$ of the respondents showed low scores on independent self and high scores on interdependent self whereas $67 \%$ of women showed high scores on independent self and low scores on interdependent self. These results showed a clear indication that Indian woman when asked on a simple 7-point rating scale reported high on independent self. The researches have already established that Indian self has both interdependence and independence but a bent towards independent self is a new feature in the context of Indian women.

\section{Meaning of Mental Health Problems}

The major themes for the meaning of mental health problems that emerged from the analysis of the obtained data were- mental health is related to a) Biological factors, Physical health and Life style issues

b) Inability to follow normal routine and perform duties in the family,

c) Emotional outbursts, and

d) Cognitive deterioration.

The meaning of mental health problems has been described by women as due to genetic factors. It was reported that depression runs in families and where mother is in depression, the children also develop such tendencies. Disturbances in mental state, problems related to thinking, reasoning and inability in expression of emotions. Irritations, aggression, late night sleep, getting up late are some more descriptions for mental health problems. Some women reported that inability to do normal household chores and too much confusion in executing our different roles are some sort of mental health problems. The respondent number 3 gave her response this way-

"A person who is not able to express his views, might be in the proper way, or is out of the social way of doing things, cannot do housework, or might be speaks something unusual, doesn't react in the way they are supposed to, that's what if it is unusual behavior, we say that there is some mental problem. It can be stress of some sort, depression; I think if you take women, specifically, it could be related to genetics also but if something is happening after marriage or after going into a different family, might be its because of some stress, strain, or if she's not able to express over a long period of time."

The physical health and fitness of the body was also considered as an important way of defining mental health. It was interpreted from the data obtained that the respondents were trying to define mental illness in a very vague way. The words to express mental anguish, emotional disturbances were not clearly communicated. Some respondents even simply expressed mental illness as inability to express one's emotions. This is reflected in responses obtained from respondent number 13.

"There are various kinds of things. See, a person can be disturbed by basically disturbance because of health, illness or probably because of mental health, or from either fooding habits, or probably you 
INTERNATIONAL JOURNAL OF ACADEMIC RESEARCH IN PSYCHOLOGY

Vol. 7, No. 1, 2020, E-ISSN: 2312-1882 @ 2020 KWP

know the day-to-day lifestyle. What we are doing is abusing our body every day, sleeping late in the night and getting up late in the morning so that's one lifestyle that we shouldn't do. So, basically it is all governed with you head right here and brains, it's all in your mind how you are, you know getting your body and mind in discipline. So, if your brain is disturbed so basically, you'll get a (mental disorder)."

From the responses obtained, it was inferred that the present educated women's notion of mental illness is not very clear. The definition involves the focus on body mind relation, deterioration of cognitive abilities, inability to do normal day routine work and special emphasize on inability to perform prescribed duties in relation to the roles they occupy in the family. The definition of mental illness itself reflect a relational nature of women's existence as some women significantly reported that the mental health of a woman is good if everyone in the family is happy with her.

Regarding the causes of mental health problems in women, it was reported that mental illness originates from the home environment, in more formal terms the psychosocial environment. The major themes identified were-

a) Suppression in the family

b) Employment of women

c) Husband's role

d) Women's perception of the psychosocial environment

Suppression in family is a universal phenomenon that was reported by majority of women respondents. The crucial factor was the family structure, women's employment and economic independence and freedom. Too much of restrictions by parents -in- laws, inability to say or decide even in front of servants, early marriage, lack of employment and hence financial independence are some of the prominent factors reported by many women respondents. It was also reported by one of the women respondent that historically since less importance was given to the women's domestic roles, men dominated women for their economic dependence on him and as a result an imbalance is created in the society. Men considered household work as irrelevant and presumed to be undertaken by women.

"People remain in problems due to household work and older members in family are dominating and cannot say anything in front of them. Humiliation in front of servants is also common and since cannot answer back so the irritation persists in mind and this irritation is the prime cause of mental illness. When my daughter went to other state for higher education, I went into depression, severe back pain was also there but back pain was treated after treatment of depression".

Education and employment of women reflects a dialectical opinion in relation to mental health problems faced by women. It was reported that women enjoys all the benefits of employment but also at the same time is overstressed due to multiple roles and subsequent role burden. Woman who goes out of the house is not free from their household duties and moreover they feel guilty if they are not able to execute their domestic duties especially as mother. Some respondents also reported that they are brought up in very open minded and liberal parents before marriage but as they acquire new roles in their husband's family, they are expected to fulfill the duties of a traditional wife and a daughter in law. Husband's role is especially important and is a decisive factor in reducing the impact of patriarchal forces on the mental health of women. One of the respondents reported this way-

"All boils down to the same thing because he's the earning member, the girl has already sacrificed, even if she is educated she is not working, so she's looking after the house and the kids and the boy is earning. So, the earning which is coming should have been like, both the partners should have had an equal right on that earning because she's also doing her share, the credit of looking after home and 
INTERNATIONAL JOURNAL OF ACADEMIC RESEARCH IN PSYCHOLOGY

Vol. 7, No. 1, 2020, E-ISSN: 2312-1882 @ 2020 KWP

children is not given to women. Men don't realize that if their wives don't look after children and home, they also can't go and work peacefully. Still the girl herself feels responsible for her house, for her kids and like give up their jobs. It's not always due to pressure by mother in law or any other family memebr, you also feel responsible yourself that I have to bring up my kids properly, and for their proper education I have to confine myself in the house".

Historically Indian women were given the right to education after a long struggle by the social reformers (Right to Education Act, 2009). Women's education and employment became an agenda for the Government of India after a long time in post independent India. The social growth of women took place very slowly and at present at least there is a steady increase in the literacy rates of women in the last 50 years (Census of India, 2011). Although women gained education and later on entered into many professional fields, unfortunately the men folk were not ready to accept the changing roles and resulted in conflict. Today education has become a mandatory need of major sections of women. The women respondents indicated in the data that education is most important for women as through education only they can be aware of their rights and can think about themselves. Illiterate women are more vulnerable to the mental health problems due to their associated helplessness. There is a special section of women whose education is stopped after marriage and as a result due to suppression of their desires, frustrations and inability to continue their education due to prominence of their domestic roles they always remain irritated and gradually goes in depression (Sinha \& Lakshmi, 1993).

One of the women reported that it is very disheartening that after being educated when women get married and she has to leave her studies for her marriage she comes to back foot and is worse than illiterate women who is more liberal and mentally tuned for how they have to lead their lives. This shows a clear indication of the double bind situations which young girls and women face in Indian society. Moreover, whenever they try to give lesser importance to their domestic roles over their education, they have to face guilt induced by the family and society leading to mental health problems. Many researches in the recent years has supported the fact that women all over the world is twice more vulnerable than men to suffer depression because of their frustrations for being not able to reach their goals due to marriage (Nolen Hoeksemo \& Girgus 1994; Sinha \& Lakshmi, 1993; and Whilhelm \& Roy, 2003).

The women respondents were also asked about the role of employment in the mental health problems. They were asked whether employed or unemployed women experience more mental health problems on which they responded that employed women has an ample opportunity to express herself, go out of the house for some time and do whatever they want at work place but an unemployed women remains confined to home and is always at target of all family members to get caught up in extended household duties. Moreover, they emphasized that women at home is always being judged by family members and this create a suffocating environment and a growing tendency for negative self esteem. The responses of both employed and unemployed women expressed that employment to a greater extent reduces the vulnerability towards mental illness as employed women are more independent and self reliant. A small section of women respondents also reflected that employed women are more vulnerable to the mental health problems because of the dual burden and difficulties in maintaining a balance between their domestic and professional roles.

"I think educated ones (are more prone to mental illness.) The reason is they are dissatisfied, illiterate ones are like dissatisfied but mentally tuned, actually in educated ones they are liberated from their parents side, they are like go do this, go do that, go and achieve this, but after marriage you have to come back to the basics which are like the same old things. I think even in highly educated, liberated, 
INTERNATIONAL JOURNAL OF ACADEMIC RESEARCH IN PSYCHOLOGY

Vol. 7, No. 1, 2020, E-ISSN: 2312-1882 @ 2020 KWP

or open families, at a point when you have to have kids you have to do it, either men or women has to leave jobs and it's always the women. I have never seen a single example of this that men leave jobs due to child birth. So, this is one reason why in educated families there is more dissatisfaction. However, in illiterate families, the girls' rights from childhood are tuned to a different life style. The mothers tell their daughters to first look after their family and children and so you are like used to that way. If you (educated ones) share (your problems) with friends then it becomes a gossip, more suffocation is there".

An important theme that came out in the present study is the women's own perception of the psychosocial environment. Some of the women's respondents indicated that it is very important that women should have a positive perception for their new family. It is a conventional practice in Indian families that girls during their marriage get an untold negative image for some new roles like mother in law and sister in law. History of cases of crime against women in the category of Husband and its family in NCRB reports indicate the significance of the two roles- husband's mother and sister. However, in the present context as the scenario is changing with increase in women's independence, authority and control over her resources as a result of economic independence, it is very important that women should also come out of the traditional moulds of new relations and see things in a more positive way. As reported by one of the respondents,

"When you get married and go to a new place, traditional women start with what is cooked, salt is more or less and all that, it starts from there, everything starts from the kitchen. But then if you understand that see you have to adjust somewhere so I think eventually time gives you all the space to get out of it but some people are there who just stay there, you know. So, that's the problem. Even there's a proverb that God helps those who help themselves. So, until and unless you won't find a midway through whatever the family problem is, there is no start to a new day. So, if you sit with that you will ten thousand problems with a negative mind if you think so everything, a person will do in a family would be a problem to that person".

The second aspect on which the present research focuses was the reasons for gender differences in mental health problems. Women respondents reported that women suffer more with mental health problems because of their emotional nature, conflict with husbands over patriarchal restraints, and their ego to maintain patriarchal social norms related to women roles in the society. Conflicts in the family due to women's working roles or autonomy and decision making are still prevalent in Indian families. Studies have also supported this fact that women and men differ in the ways they communicate, deal in relationships, express their feelings and respond to stress. Therefore, the gender differences are based in physical, physiological and psychological attributes (Delina \& Raya, 2013). Other psychosocial variables reported to be responsible for more mental health problems in women are partner alcohol use, sexual and physical violence by the husband, being widowed or separated, having low autonomy in decision making, and having low levels of support from one's family (Patel et. al., 2006; Shidhaye \& Patel, 2010; Nayak et. al., 2010). Therefore, it can be inferred from these results that the present educated contemporary Indian women, despite moving ahead with all opportunities and aspirations and also trying to fulfil them but due to strong social construction of gender, it becomes difficult for them to leave their traditional or relational self ideologies and as a result end up in a state of flux. On probing, women also reported that it is very difficult for Indian women to come out of the existing moulds that is in comparison to men, it is difficult for women to deny the social norms and rules and as a result even if they want to assert their individual self they have to go with the group or show interrelatedness in order to maintain peace in 
their families. This seems to be the most disturbing feature of women's psychosocial environment where she feels suffocated and cannot show any autonomy.

The causes of mental health problems in the present study are indicative of the fact that even when the woman in India is passing through a transitional phase and moving from her traditional to modern roles, the conflicting situations are still prevailing and patriarchal mindsets are still prevailing and affecting the mental health of women. Orthodox thinking in Indian families, overemphasize on women's domestic duties, lack of family support in taking a decision and lack of economic independence still occupy strong position in the factors associated with poor mental health of women. Studies have shown that females are more predisposed to mental illness due to rapid social change, gender discrimination, social exclusion, gender disadvantage like marrying at young age, husband's substance abuse, domestic violence etc (Patel \& Kleiman, 2003). These results infer that hardly any change has taken place in the causes of mental health problems when compared to what was reported by women in the researches done during 1980-2000. Moreover, the limited awareness and resistance to accept the mental health problems in any of the family members is one of the crucial factors in the seriousness of mental health problems especially in Indian context.

\section{Conclusions and Implications}

The results of the study indicate that the women perceive psychosocial environment as major cause of mental health problems in India. They consider women's education, employment and their work home balance as determining factors in causation of mental health problems. Moreover, the study gives a clear indication that the different roles played by women in her life are very important in understanding the etiology of mental health problems in later life. The complexity of the roles expectations and roles conflict puts woman in a demanding and stressful situation leading to an increase in the mental health problems. The self of the women is showing a transition towards individuality however their narrations indicates a guilt for being an individual identity so she compromises and adjust in the relational being. The Indian society is changing very fast and there is a need to understand the transitions in the Indian women's psyche with reference to their selves. These results of the study imply that there is a need to sensitize the men folk to understand the changing needs of women in their psychosocial environment and to consider them as being who is not always "in relation" but as an "independent identity". The women's interdependence nature of self reflects that it is difficult for women to come out of the traditional definitions of roles occupied by her in her psychosocial environment.

\section{References}

Afifi, M. (2007). Gender differences in mental health. Singapore Medical Journal 48(5), 385-91.

Aminabhavi, V. A., \& Kulkarni, V. R. (2000). Mental health of working women and housewives. Praachi Journal of Psycho-cultural Dimensions, 16(1), 33-35.

Aujla, H. P. (2002). Mental stress management techniques: An analysis among working and nonworking women. Behavioural Scientist, 3(2), 125-127.

Basu, S. (2012). Mental Health Concerns for Indian Women, Indian Journal of Gender Studies, 19(1), 127-136.

Crime in India. (2018). Statistics Volume I. National Crime Record Bureau, Mahipalpur, New Delhi.

Cross, S. E. (2000). The Relational Interdependent Self Construal and Relationships. Journal of Personality and Social Psychology, 78(4), 791-808. 
INTERNATIONAL JOURNAL OF ACADEMIC RESEARCH IN PSYCHOLOGY

Vol. 7, No. 1, 2020, E-ISSN: 2312-1882 @ 2020 KWP

Delina, G., \& Raya, R. P. (2013). A Study on Work Life Balance in Working Women. International Journal of Commerce, Business and Management, 2(5).

Dutt, A. K., \& Noble, A. G. (1982). The Culture of India in Spatial Perspective: An Introduction. In A.G. Noble \& A.K Dutt (Eds), India: Cultural Patterns and Processes (pp1-28). Boulder CO: West View.

Kumar, S. C., Gupta, S. D., \& Abraham, G. (2002). Masculinity and Violence against Women in marriage: An exploratory study in Rajasthan. In ICRW (Ed.), Men, Masculinity and Domestic Violence in India: Summary Report of Four Studies, (pp6-15). Washington, DC: International Centre for Research on Women.

Kumari, P., \& Singh, A. P. (2000). Life stress and some personality variables: A Comparison of Working Women and Housewives. Journal of the Indian Academy of Applied Psychology, 26(1-2), 2531.

Maas, J., Van Assen, M. A. L. M., Van Balkom, A. J. L. M., Rutten E. A. P., \& Bekker, M. H. J. (2019). Autonomy-Connectedness, Self Construal, and Acculturation: Associations with Mental Health in Multicultural Society. Journal of Cross Cultural Psychology, 50(1), 80-99.

Markus, H. R., \& Kitayama, S. (1991). Culture and the Self: Implications for cognitions, emotion, and motivation. Journal of Personality and Social Psychology, 98, 224-253.

Medicine. (1957-1973). Mental Health: Problems, priorities and responses in low- income countries. 55(11).

Michelle, K., Helen, H. R. A., Joshua, W. R. P., \& Patel, V. (2007). Empowerment of women and mental health promotion: A qualitative study in rural Maharashtra, India. BMC Public Health. 7(1), 225.

Nayak, M., Patel, V., Bond, J., Greenfield, T. (2010). Partner alcohol use, violence and women's mental health: A population based survey in India. British Journal of Psychiatry, 196, 192-9.

Nolen, G., \& Hoeksena, S. (1994). The emergence of gender differences in depression during adolescence. Psychological Bulletin, 115, 423-43.

Rao, V. (1997). Wife-Beating in rural south India: A qualitative and econometric analysis. Social Science and Medicine, 44(8), 1169-1180.

Saha, S., \& Safri, T. (2016). Cinderella Complex: Theoretical Roots to Psychological Dependency Syndrome in Women. International Journal of Indian Psychology, 3(3), 8.

Shidhaye, R., \& Patel, V. (2010). Association of socio-economic, gender and health factors with common mental disorders in women: a population-based study of 5703 married rural women in India. International Journal of Epidemiology, 39, 1510-21.

Singelis, T. M. (1994). The measurement of independent and interdependent self- construals. Personality and Social Psychology Bulletin, 20, 580-591.

Sinha, R. B. N., \& Lakshmi, R. (1993). Sex differences in depression. Perspectives in Psychological Researches, 16 (1\&2), 49-50.

Suzuki, S., Takei Y. (2013) Psychosocial Factors and Traumatic Events. In: Gellman, M. D., Turner, J. R. (Eds.) Encyclopedia of Behavioral Medicine. Springer, New York, NY.

Patel, V., Betty R., Kirkwood, S. P., Weiss, H., \& Mabey, D. (2006). Risk factors for Common Mental Disorders in Women - Population Based Longitudinal Study. British Journal of Psychiatry, Vol. 189, 547-555. 
Vindhya, U. (2007). Quality of Women's Lives in India: Some Findings from Two Decades of Psychological Research on Gender. Feminism \& Psychology, 17(3), 337-356.

Vindhya, U., Kiranmayi, A., \& Vijayalakshmi, V. (2001). Women in Psychological Distress: Evidence from a Hospital-based Study. Economic \& Political Weekly, 36(25), 4081-4087.

Whilhelm, K., \& Roy, K. (2003). Gender Differences in Depression Risk and Coping Factors in a Clinical Sample. Act Psychiatric a Scandianic. 106, 45-53.

Wills, L. A., \& Petrakis, M. (2019). The self in motherhood: a systematized review of relational selfconstrual and wellbeing in mothers. Advances in Mental Health, 17(1), 72-84.

World Health Organization. (1981). Social Dimensions of Mental Health (5). Geneva.

World Health Organization. (2001). Mental Health: New Understanding; New Hope. WHO, Geneva. 